Para enlazar con este artículo / To link to this article:

http://dx.doi.org/10.14198/fem.2018.31.10

Para citar este artículo / To cite this article:

Núñez, Paula Gabriela. "Feminismo de frontera. La construcción de lo femenino en territorios de integración tardía". En Feminismo/s, 31 (junio 2018): 205-230, DOI: 10.14198/fem.2018.31.10

\title{
FEMINISMO DE FRONTERA. LA CONSTRUCCIÓN DE LO FEMENINO EN TERRITORIOS DE INTEGRACIÓN TARDÍA ${ }^{1}$
}

\section{BORDER FEMINISM. THE CONSTRUCTION OF FEMALE IN LATER INTEGRATED TERRITORIES}

\author{
Paula Gabriela NúÑEZ \\ Universidad Nacional de Río Negro, Argentina \\ http://orcid.org/0000-0002-2008-2643
}

\section{Resumen}

Este trabajo propone el concepto de feminismo de frontera, para dar cuenta de sesgos específicos de la desigualdad de géneros en territorios de integración tardía, tomando como caso de estudio la Patagonia. Los principales antecedentes conceptuales son los de los feminismos negros y los ecofeminismos, que introducen procesos de feminización de la tierra y el paisaje. Se revisan fuentes militares y científicas del proceso de apropiación estatal del territorio. Se analiza cómo el reconocimiento del paisaje se traslada a las poblaciones que, más allá de su sexo, resultan feminizadas por el sitio de subalternidad que se les otorga en la estructura estatal. Como conclusión se demuestra que la pertenencia territorial se resignifica en articulación con discriminaciones por etnia, género y clase, que en estas regiones se naturalizan por una referencia al paisaje antes que a vínculos sociales.

Palabras clave: Feminismo de frontera, feminización de la tierra, feminismo negro, ecofeminismo, territorios de integración tardía.

1. Este artículo se elaboró en el marco del proyecto PIP 0838 (CONICET-Argentina).

Los contenidos de la revista se publican bajo una licencia de Creative Commons Reconocimiento 4.0 Internacional (CC BY 4.0)

Feminismo/s 31, junio 2018, pp. 205-230 
Feminismo de frontera. La construcción de lo femenino en territorios de integración tardía

\begin{abstract}
This manuscript introduces the concept of border feminism in order to observe the specific biases of gender inequality in later integrated territories, taking Patagonia as study case. The main theoretical backgrounds are black feminisms and ecofeminisms, which introduce the processes of feminization of the land and the landscape. It reviews military and scientific sources in State land appropriation process. It researches how the recognition of the landscape is transferred to populations, which beyond their sex, are feminized because of subalternity location that is given to them by the State structure. As a conclusion, it shows that the territorial belonging is resignified in articulation with ethnicity, gender and class discrimination, that in these regions are naturalized by a reference to the landscape rather than to social ties.
\end{abstract}

Keywords: Border feminism, land feminization, black feminism, ecofeminism, later integrated territories.

\title{
1. INTRODUCCIÓN
}

A lo largo de este trabajo exploramos cómo la construcción de la subalterindad femenina no sólo se establece en base a los cuerpos, sino también a modos de valorar y habitar el territorio. Nos preguntamos por las especificidades de esta subalternidad en el caso particular de la Patagonia, observando las herencias de la conquista efectivizada a fines del siglo XIX y evidenciando su incidencia en lo que se busca fijar como parte constitutiva del lugar. El espacio patagónico fue considerado como frontera de integración tardía respecto del resto del mapa estatal (Navarro Floria, Territorios 207), por ello denominaremos "feminismo de frontera" a la mirada crítica del particular paternalismo consolidado a partir de este reconocimiento.

Cabe destacar que la noción de frontera se apoya en los sentidos en que fue comprendida en relación a la integración territorial. El sur del continente se integra en el concierto nacional cuando el país ya tenía establecido el orden republicano. El argumento para unir la Patagonia a la Argentina involucra un sentido complejo y abierto de la frontera, pues el territorio como conjunto se marca como el límite de los Estados nacionales frente al control de pueblos

Feminismo/s 31, junio 2018, pp. 205-230 
originarios $^{2}$. La frontera es una frontera interna que proyecta la dicotomía civilización/barbarie con la que Sarmiento ${ }^{3}$ explicó la conformación argentina. En este sentido es una frontera con un orden que se concibe opuesto al que se intenta instalar desde el Estado.

Pero además, la conquista de la Patagonia se propone hacia una frontera nacional, pues desde las últimas décadas del siglo XIX se reconoce una disputa por el control del territorio cordillerano entre Argentina y Chile. Así que también es línea, además de territorio, abriendo retóricas cambiantes en los documentos estatales que permiten deslizar fundamentos de control interno a la idea misma de marcar los límites formales del país. Esta frontera nacional a construir está geográficamente lejos de la frontera que se habita en la "defensa contra el indio" y que se presenta como problema. Desde ese sentido de conquista y control recorremos la particular vinculación en una construcción de la subalternidad que involucra género y etnia.

Las prácticas y sentidos estudiados abren puentes entre la caracterización del ambiente y de las mujeres, por ello nos pondrán en diálogo con el ecofeminismo en tanto se discute el vínculo naturaleza-mujer desde el de territorio-mujer. Territorio y naturaleza no son sinónimos, pero en su homologación a la idea de mujer devienen equivalentes en tanto la "naturaleza" de la mujer es referencia para interpretar "lo natural" del espacio desplegado en el territorio ${ }^{4}$.

Núñez (Distancias 173-181) observa que lo recortado como naturaleza deviene en "lo natural", esto en "normal", para instituirse en "norma" de orden y comportamiento social. En Argentina, el pase del territorio al cuerpo tiene otra connotación. Como observa Quijada, a lo largo del siglo XIX la propia identidad nacional se fundamentó en la comprensión del territorio devenido en norma (375).

2. Foerster y Vezub señalan que a mediados del siglo XIX esas regiones se consideraban argentinas, aún con un control incompleto (265-266). Para finales de siglo se plantean antagónicas al Estado.

3. Político y pensador Argentino de enorme influencia en el siglo XIX. Su obra emblemática es Facundo. Civilización o Barbarie en las Pampas Argentinas, 1845.

4. Entendemos que la noción de espacio apela al ideal cuantificable y el territorio al reconocimiento de la producción social del mismo (Haesbaert 15)

Feminismo/s 31, junio 2018, pp. 205-230 
En el presente trabajo revisaremos los escritos científicos y técnicos que presentan el territorio patagónico, observando en ellos los sesgos en la construcción de lo femenino. Tomaremos el primer estudio sistemático del país que dibuja y describe el territorio y la población patagónica, el de Napp de 1876, para sumar los escritos militares y científicos elaborados durante la iniciativa considerada la conquista definitiva sobre el espacio, la avanzada militar de 1879 conocida como "Campaña al Desierto". Los informes científicos contratados para realizar estudios en el espacio, se ponen en diálogo con las memorias de militares, donde la compilación de Raone en 1969 se presenta como una de las más completas. Sumamos reflexiones de observadores recuperadas en estudios posteriores, como el de Ramayon de 1914, así como romances y folclores desde los cuales se ha buscado rescatar a las figuras femeninas, explorados en los escritos contemporáneos de Dillon, Ockier y Pichel.

Ahora bien, los territorios, como las mujeres, no son todos iguales. Ello no es únicamente por su variedad en geografías, que sería asimilable a plantear la diferencia de las mujeres exclusivamente por factores físicos. La diferencia territorial a la que apelamos en este trabajo, constitutiva de la desigualdad, tiene que ver con la estructuración de un colonialismo interno que se sostendrá en el tiempo (Navarro Floria, Territorios 220).

En este punto, el caso patagónico permitirá evidenciar que la vinculación colonial, en un territorio cuya subalternización se explica por su paisaje, se apoya en metáforas de género que inicialmente apelan a un imaginario de mujeres ancladas en el estereotipo de quienes sostuvieron el avance estatal. En estos estereotipos se reconoce la particularidad del sexismo que fundamentó regionalizaciones internas y el establecimiento de políticas específicas de control social.

Núñez ("The 'She Land" 1445-1446) observa que los planes de desarrollo de Patagonia a lo largo del siglo XX se justificaron desde metáforas que vincularon la caracterización del territorio a determinados estereotipos femeninos. Así reconoce tres imágenes retóricas. 1- La "fortinera, india o paisana" asociada al reconocimiento de las zonas rurales de secano. 2- La "madre nutricia", explícita en los espacios de producción frutihortícola, o ganadera en el área de la Patagonia chilena. 3- La "princesa o frágil burguesa", 
referencia de las áreas naturales protegidas. En los tres casos observa que la feminización se liga a un modo de inscribir el territorio como frontera interna.

En el presente escrito nos detendremos en la primera imagen, la de la "fortinera", mostrando cómo esta referencia estructura el proceso de asimilación territorial. La forma de conocer, y su posterior proyección en los sucesivos ordenamientos territoriales, será el camino por el que las metáforas sexistas devienen en política pública.

\section{FEMINISMO DE FRONTERA}

La noción de "feminismo de frontera" no remite al "feminismo fronterizo" que apela a la movilidad de la población femenina en escenarios actuales. Reconoce un claro antecedente en el concepto que Saldivar-Hull presenta en 1991, de "feminism on the border", que liga patriarcado, capitalismo y supremacía blanca, llamando la atención hacia aspectos raciales y étnicos, que evalúa como históricamente silenciados en el feminismo liberal.

La noción desarrollada en este trabajo va a adoptar aristas del trabajo de Saldivar-Hull, pero en una clave que lo relaciona con análisis ecofeministas, en tanto refiere a la frontera como naturaleza, que en el caso que nos ocupa implica vivir en áreas de control débil por parte de la organización institucional, afectada por dinamismos de órdenes alternativos, donde lo femenino se explicita como base fundamental para la posibilidad misma del vivir, en un ambiente visto como hostil.

Las regiones y poblaciones que nos ocupan son áreas donde el patriarcado deviene en la promesa y posibilidad del capitalismo ${ }^{5}$, entendido como oportunidad única de progreso, y donde la supremacía blanca refiere a un ideal urbano que queda muy lejos. Es un espacio que sobrecarga los sentidos de esfuerzo y abnegación, que llevan a reparar en las particularidades de lo construido como "mujer".

5. El presente análisis no presume que el paternalismo y el sexismo constituyen exclusivamente el orden capitalista. Diversos estudios, como los de Vera Gajardo o Sckmunck dan cuenta de diferencias de género en el interior de los pueblos originarios patagónicos, que en la actualidad se toman problemáticamente como parte de la cultura.

Feminismo/s 31, junio 2018, pp. 205-230 
Feminismo de frontera. La construcción de lo femenino en territorios de integración tardía

Partimos de la noción de feminización de la tierra (Lee y Madden; Hunt y Rygiel; Lewis y Mills; Núñez, "The 'She-Land"), desde la cual se revisan las metáforas que ligan mujer y territorio, y que son fundamento de las políticas que consolidan apropiaciones asimétricas.

Vale destacar que esta asociación de desigualdades, que liga territorios a mujeres, no se circunscribe a la Patagonia. Pero la Patagonia, instalada como frontera en múltiples sentidos ${ }^{6}$, se establece como territorio donde el peso del ambiente y el paisaje aún aparecen como sobredeterminantes en justificativos de planes de desarrollo. La historiografía regional ha mostrado como, a lo largo del tiempo, se repite una carga de subalternidad que mezcla territorios y poblaciones (Iuorno y Crespo; Nouaeillez; Navarro Floria).

Este territorio se ha evaluado como dependiente de un manejo externo por su "integración tardía", en tanto fue incorporado a fines del siglo XIX, con el Estado nacional ya conformado ${ }^{7}$. La población, varones y mujeres que viven en ese espacio, es subalterna porque se la presenta como carente de capacidad de autonomía y administración. Esto recorre argumentos que apelan a la idea de sociedad joven, y por lo tanto irracional, que justificó la imposibilidad de acceso a elegir autoridades o tener representantes en las cámaras legislativas hasta la segunda mitad del siglo XX.

Esa carencia de capacidades es argumento de apertura al paternalismo estructural que entendemos como una feminización general de la población porque no sólo infantiliza a los habitantes en términos de derecho, sino que inscribe buena parte de las actividades en el sitio de la no-producción, simplemente ajenas al modelo económico que se instalaba ${ }^{8}$, valorando las mismas como parte de los órdenes reproductivos o culturales.

6. Navarro Floria (Territorios 215-222) reconoce tres acepciones. 1-Como frontera de la aridez, ligada a la idea de desierto que reduce un enorme territorio a una particular condición ambiental; 2- como frontera de la civilización, base argumentativa del proceso de conquista; y 3- como frontera nacional.

7. La independencia de Argentina se firma en 1816, la incorporación de la Patagonia en 1884.

8. Actividades de trashumancia, propias de la cordillera patagónica, o de agricultura familiar se cuentan como ejemplo. A ello se suma el turismo, desconocido como actividad económica en las planificaciones estatales hasta la década de 1990.

Feminismo/s 31, junio 2018, pp. 205-230 
Otra área de estudios en que se apoya esta noción es la de los "feminismos negros" latinoamericanos ${ }^{9}$. Este análisis discute el armado institucional de los países atravesados por el esclavismo. Los feminismos negros revisan varios elementos raciales, que los acercan a lo propuesto como "feminismo de frontera" en las reflexiones de las feministas chicanas. Ellas reparan en un proceso profundamente latinoamericano, que se articula con la construcción territorial. Los feminismos negros en Latinoamérica revisan especialmente el proceso independentista, observando el ocultamiento de la situación de esclavitud de las mujeres, evidenciando cómo en esos años se debilitó la demanda feminista del naciente feminismo liberal en estos espacios (Barriteau 8). Los discursos de libertad, aun cuando convocaban a sectores subalternos para unirse a la lucha antiespañola, reclamaban la libertad de comercio y los derechos de las oligarquías consolidadas, así cristalizaban un ordenamiento social jerárquico, racista y sexista (Núñez, Trazado 68).

De aquí introducimos como punto de origen de los "feminismo de frontera" el proceso por el cual la particular comprensión de las mujeres que forman parte del avance estatal en el territorio, las que habitaron las fronteras en la demarcación del territorio como argentino, devienen en referencia de la tierra que se conquista y organiza, para de allí avanzar reflexionando en cómo las lógicas del paternalismo se modifican en función de las diferentes imágenes que estereotipan el terrritorio. Los caracteres que se reconocen en las mujeres se re-proyectan hacia el territorio, y la apropiación del territorio se puede vincular a la apropiación de esos cuerpos, que devienen en la metáfora del cuerpo social.

Podría pensarse que en esa dinámica de apropiación, que cruza cuerpos y paisajes, se observa operativamente la compleja co-constitución entre sexo y género denunciada por Butler. La autora indica que el género es el medio cultural a través del cual el sexo se establece artificialmente como prediscursivo. En el caso que nos ocupa, el paisaje claramente, y el proceso de conquista en sí, implícitamente, presuponen un horizonte prediscursivo en tanto hay un

9. Esta línea de investigación es deudora de los feminismos negros norteamericanos, que reconocieron elementos de racismo en las reivindicaciones sufragistas del siglo XIX, entre otros elementos, en lo que Rich en 1979 denominó "solipsismo blanco del feminismo" (299).

Feminismo/s 31, junio 2018, pp. 205-230 
Feminismo de frontera. La construcción de lo femenino en territorios de integración tardía

modelo de desarrollo capitalista que se inscribe como natural, así como una jerarquía social racista y sexista que se considera dada.

\section{POSTALES DE LAS FORTINERAS}

Las fortineras son mujeres que han sido presentadas como fundamentales para la apropiación territorial, en tanto se las consideró, en su época, constructoras de la posibilidad misma del sobrevivir. Sin embargo, los numerosos estudios relativos a la apropiación patagónica se refieren a ellas poco y nada. Dillon indica que las fortineras argentinas se encuentran en la poética y el teatro por haber sido omitidas por la historia como sujetos económicos o políticos. Ockier introduce matices en la forma de reconocimiento de estas mujeres. Así observa que las fuentes de mediados del siglo XIX, ligadas a los enfrentamientos sectoriales del país en formación, las ubican como responsables de los vicios de los soldados. La misma autora caracteriza un giro en este relato, cuando unas décadas más tarde, el heroísmo de la gesta de la conquista de la guerra contra los indios se traslada hacia esas mujeres, como reflejos del esfuerzo que implicaba el avance militar y de la política de argentinidad que se reivindicaba.

Raone, en un extenso recorrido por las fuentes militares producidas para y durante la Campaña de $1879^{10}$, y como homenaje a la misma, va a reparar especialmente en la figura femenina. El autor asume que en esta conquista se encuentran "los valores inmanentes de la nacionalidad" (1: 9). En su escrito, el avance se presenta como una gesta que se despliega entre caracteres estereotipados de lo femenino y lo masculino. El autor ubica a los varones frente al poder de las armas, la capacidad de lucha y en las arenas políticas internas de las parcialidades indígenas. Como contraparte, el peligro de la frontera y la fragilidad del fortín adquirían una reminiscencia femenina, que operaba como marca en los cuerpos de las mujeres que los poblaban. El autor señala que en esos escenarios de peligro, más que en ningún otro lugar "Se sufría por la Patria. ¿Qué era esto de Patria? Un ideal, una fe. Por ella se peleaba

10. La conquista militar de 1879 es la de mayor impacto en la memoria oficial y social, en tanto fue la definitiva para establecer el dominio del gobierno argentino sobre el territorio. Fue la avanzada dirigida por el general Julio A. Roca, que en sólo un año estableció un control casi completo, en lo que se autodenominó "Campaña al desierto".

Feminismo/s 31, junio 2018, pp. 205-230 
con la bravura que se pelea por el amor. La Patria y la mujer son hembras. Y el gaucho que hace de milico en el fortín es varón" (1: 48).

La mujer se descubre con un carácter doble que nos remite a los elementos de supremacía blanca, referidos en los feminismos étnicos. La Patria, en su necesidad de protección, es mujer en las áreas de frontera. Es mujer burguesa y débil, que se va consolidando como estereotipo de las poblaciones urbanas, que por su fragilidad debe protegerse en esas regiones de peligro, y por ello se debe erradicar el peligro. Y ese "erradicar" es tarea de varones. Porque ella, en su debilidad, lo único que hace es yacer.

Ahora bien, la mujer que vive en esa frontera frágil no es un ser débil o necesitada de cuidado. Raone rescata múltiples fuentes que van a destacar esfuerzo, capacidad, astucia y heroísmo de "las milicas", sin las cuales se planteaba imposible planificar la apropiación territorial. El autor refiere, por ejemplo, a la indicación que los reclutas debían ser casados. Se refiere a la milicia criolla denominada "cuerpo de blandengues", dedicada a la defensa contra el indio, y no necesariamente abocada al avance sobre el territorio. En relación a los mismos se decía que debían contar con un terreno aledaño al fuerte, además de fondos para establecer la vivienda, de modo de afincar el compromiso de la defensa de la frontera en su círculo de afectos más cercano (Raone 1: 94). No hay soporte y defensa sin mujeres. Las mujeres de los milicianos, desde esta perspectiva, eran anclaje de estabilidad, y eran "de" ellos.

Las cuatro mil mujeres que acompañan el ejército en movimiento de 1879 no tienen estos lugares fijos. Ya no se ocupan por el traslado del orden doméstico a un escenario similar, sino que adoptan caracteres cambiantes. Muchas veces, en este escenario dinámico, son reconocidas como parte de la tropa. Alejadas explícitamente de la imagen frágil impuesta a la mujer burguesa, se las valora por "[...] saber tener en todas las circunstancias la fortaleza de carácter y el ánimo mismísimo del milico" (Raone 1: 95).

La fortinera, como mujer que acompaña el ejército, ha sido problematizada por Ockier desde la figura de la prostituta que debilita el carácter moral de la tropa; ha sido presentada por Raone como la esforzada heroína, pero nunca fue descripta como frágil burguesa. La fortinera es parte estratégica de la conquista, como la ciencia y las armas.

En este punto se despega de la débil "Patria-mujer", precaria en las fronteras marcadas por una arquitectura transitoria, de materiales degradables, 
sobre terrenos en disputa. Las fortineras ponían su esfuerzo, asimilado al masculino, por esa otra Patria-mujer frágil, que en su debilidad les impedía hasta el derecho del descanso.

Ahora bien, la noción de raza que opera en los fortines, desde la mirada estatal, no es homologable a la de los feminismos étnicos latinoamericanos o norteamericanos, pues aunque muchas fortineras eran secuestradas de poblaciones originarias destruidas, otras tenían orígenes diferentes, sin que las fuentes den cuenta de estas distinciones. En la mirada sobre la frontera, la raza pareciera tener una connotación masculina. Es decir, son los varones quienes detentan los caracteres de la raza, y no las mujeres, quienes en la particular feminización que las cubre pierden desde los fenotipos hasta los nombres, pues la memoria las rescata desde sus apodos (Ockier; Raone, vol. 1). Esto no significa que no hubiera racismo, sino que estuvo diferenciado por elementos sexuales.

Este punto se observa si nos detenemos en los escritos científicos que acompañaron la apropiación de la Patagonia. Los estudios feministas sobre ciencia hace muchos años han dado cuenta del sesgo androcéntrico en la producción científica (Bordo). En el caso de la Patagonia, los primeros estudios tienen, además, un carácter bélico, en tanto se proponen en diálogo con la posibilidad de apropiación militar. Ahora bien, algo del orden de lo pre-discursivo se instaura como parte de la significación que se desarrolla.

Lo deseable se plantea como un destino prefijado. Lois ha caracterizado la manipulación que inscribe las intensiones en mapas, como si fuese parte de la geografía, en dos operaciones que denomina como "ficción cartográfica" y "deseo territorial". El destino del deber-ser, en la tierra patagónica, fue delineado desde antes de la conquista y se considera pre-dado, remitiendo al orden prediscursivo de la idea de sexo de Butler en la comprensión del territorio.

La Patagonia, sin conocerse, se supone tierra de agricultura. El primer texto que mapea las tierras del sur como argentinas es el de Napp de 1876. Allí se explicita el desconocimiento absoluto de la región. Sin embargo se menciona el territorio para el desarrollo de la agricultura y la ganadería, marcando que no hay posibilidad de pensar algo diferente.

Los resultados de la exploración entre 1876 y 1877 al sur, realizada por el perito de límites Francisco Moreno, refieren a un desconocimiento total como 
antecedente y presentan referencias sistemáticas a un futuro de producción agrícola en análisis que focalizan calidad de suelo, clima o acceso al agua. La no existencia de agricultura se justifica en la raza. Pero la raza se presenta con la diferencia sexual mencionada. Moreno señala la falta de capacidad de hacer de los varones nativos pero reconoce el esfuerzo de las labores femeninas, responsables de todos los arreglos domésticos. Las va a homologar a las mujeres "civilizadas", por su permanente cuidado familiar. Pero esto no afecta su evaluación. No hay posibilidad de desarrollo con esta población, a decir de Moreno, por la falta de actitud productiva de los varones, aún cuando menciona al pasar la capacidad productiva de las hilanderas y tejedoras (35). Lo femenino es permanentemente subalterno, y aunque desde Moreno cruza civilizaciones en su reivindicación de la maternidad, no hay capacidad reconocida, en tanto el quehacer se plantea de un orden doméstico no comercial. La capacidad doméstica-femenina, aun con todo el esfuerzo reconocido, no es pensable como base de cambio posible.

Este punto remite al escrito de Sarmiento, de 1845, quien liga las industrias en manos femeninas a los elementos de barbarie de las provincias. El trabajo-esfuerzo femenino es condición del capitalismo, pero la gestión femenina es opuesta al orden capitalista en armado. El trabajo de las fortineras, además, recordaba un control que no se terminaba de tener. Así, si el trabajo femenino no era eclipsado, el progreso parecía imposible ${ }^{11}$.

En 1893, el naturalista argentino Guillermo Hudson plantea que a pesar de toda la capacidad reconocida en el registro lítico, los actuales habitantes de la Patagonia, herederos de quienes modificaron piedras y espacios, son una "raza" mucho más débil sólo por su contacto con una "raza superior". La capacidad de hacer se encuentra en dos orígenes espurios: en mujeres, que

11. El ocultamiento del trabajo femenino está en el armado estatal en estos años. En el primer Censo Nacional, en 1869, se buscó relevar todas las actividades sin diferencias el sexo, incluida la prostitución (De la Fuente, Primer XLV). En 1895, en el segundo Censo Nacional, se decide que el trabajo femenino refleja debilidad en el país y se plantea como error metodológico del relevamiento del censo previo, y por ello se relevó trabajo femenino sólo en el caso que no existiera ingreso masculino en la unidad doméstica, no importaba cual fuera la actividad de la mujer (De la Fuente, Segundo XXXVIII).

Feminismo/s 31, junio 2018, pp. 205-230 
Feminismo de frontera. La construcción de lo femenino en territorios de integración tardía

son contrapuestas al orden patriarcal a establecer ${ }^{12}$, y en tiempos remotos, que son inaccesibles.

El capitalismo demanda la destrucción de los órdenes establecidos, y la Campaña militar se organiza explicitando esto. Vale mencionar que 1879 no sólo es el año en que se realiza la conquista que se considera definitiva, sino que también es la primera instancia en que se toman colecciones sistemáticas para organizar el conocimiento del territorio.

La comisión científica que acompañó a las tropas recogiendo, identificando y categorizando todo tipo de plantas, animales y minerales merece un detalle aparte ${ }^{13}$. En la introducción al texto de esta comisión, redactada por el Ingeniero Ebelot ${ }^{14}$, se plantea una continuidad directa entre ciencia y conquista, entendiendo que la guerra sólo es posible en tanto se la entienda sometida "[...] al método severo de la ciencia esperimental." (VIII). Navarro Floria (Patagonia) explora el carácter utilitarista del colonialismo asociado al proceso de conquista, elemento que se explicita en la introducción de Ebelot:

Era necesario conquistar real y eficazmente esas 15,000 leguas, limpiarlas de indios de un modo tan absoluto, tan incuestionable, que la mas asustadiza de las asustadizas cosas del mundo, el capital destinado á vivificar las empresas de ganadería y agricultura, tuviera él mismo que tributar homenaje á la evidencia, que no esperimentase recelo en lanzarse sobre las huellas del ejército espedicionario y sellar la toma de posesión por el hombre civilizado de tan dilatadas comarcas. (XI)

El "capital destinado á vivificar las empresas de ganadería y agricultura" es el actor del cambio, para él (masculino) se organiza la conquista. A diferencia

12. La particularidad reconocida al paternalismo capitalista no implica a la equidad de género como escenario precedente. Este tema es base de un extenso debate que refiere al problema de la negación del androcentrismo histórico en una suerte de esencialismo estratégico donde a las mujeres racializadas se les encomienda encarnar la tradición de sus pueblos (Vera Gajardo 9).

13. La misma estuvo conformada por el botánico Pablo Günther Lorentz, el ayudante de botánica Gustavo Niederlein, Adolfo Döering, zoólogo y geólogo y el preparador de zoología Federico Schulz, todos nacidos en Alemania y vinculados a la Universidad de Córdoba. Como resultado se publicaron tres tomos publicados entre 1881 y 1884. Estos estaban divididos temáticamente en Zoología, Botánica y Geología.

14. Ingeniero francés contratado por Argentina para la construcción de la primera defensa estructural "contra los indios".

Feminismo/s 31, junio 2018, pp. 205-230 
del carácter aguerrido y valiente de las fortineras, el capital es cobarde, y en esa cobardía es racional. La valentía, en este escenario, parecería adoptar un carácter de barbarie.

Ciencia, conquista y desarrollo son claramente labores masculinas, lo femenino quedó naturalizado en ese cúmulo de condiciones de posibilidad donde se inscribió la geografía ${ }^{15}$. La agencia, sea por el peligro, sea por la acción, es masculina, lo humano se reduce al hacer del varón.

La Patagonia se presenta a la conquista como ocupada por una "raza estéril" (Ebelot XX). Pero allí la raza alude a lo masculino adulto que debe destruirse. Indias y niños eran llevados a los fortines o repartidos en distintos puntos de civilización. Estas parcialidades subalternas no detentan el carácter estéril citado.

La frontera, como área de lo posible pero no hecho, queda en esa ambigua figura que reconocemos de lo femenino. En el límite de aquello que marca un deber-hacer, pero que en su existencia demuestra la incapacidad presente del lograrlo. Así la existencia de la línea de fortines no era muestra del avance del país, era más bien marca de los límites de la política de avance. Este es un argumento paradojal que introduce el justificativo del paternalismo. El Estado devendrá poderoso en cuanto estas debilidades no existan y esa compleja fuerza femenina se desdibuje en el armado del país.

Las introducciones a los tratados de Zoología (Döering) y Botánica (Lorentz y Niederlein) que resultan de la Campaña de 1879, señalan el riesgo de la frontera, Döering indica que "cada paso progresivo hacia el límite de estas regiones, era inscrito en la historia con la sangre de innumerables víctimas, sacrificadas á la inclemencia del salvage." (4).

Lorentz y Niederlein, por su parte, mencionan que

Los indios salvajes [...] habrían hecho pagar con la vida al explorador que se hubiese atrevido á llegar hasta sus tolderías.

15. Harvey señala que en la noción misma de progreso está implícita la reducción del espacio a una categoría contingente. Retoma en este sentido una pregunta de Foucault, al decir que el francés "se pregunta cuándo y por qué el espacio fue tratado como lo muerto, lo fijo, lo no-dialéctico, lo inmóvil mientras que el tiempo, por el contrario, era la riqueza, la fecundidad, la vida, la dialéctica. (230) 
No existía entonces un General ROCA, para abrir estas vastas regiones tanto á la civilización y á la industria, como también á la ciencia... Nosotros, en una marcha rápida invernal de menos de 3 meses, pudimos recojer mas de 300 especies; y la experiencia ha demostrado que estos desiertos, tan mal afamados, son regiones fertilísimas. (175)

Los autores conocen trabajos previos, como los de Francisco Moreno, quien explicita su propia experiencia viviendo en comunidades patagónicas, donde el antagonismo con la población originaria no era tal. Pero todo esto se omite en la posibilidad de conocimiento que se plantea en estos informes técnicos.

Los estudios sobre la investigación científica han dado cuenta de su carácter utilitario (Navarro Floria, Patagonia; Podgorny), además del reconocimiento del rol heroico que se adjudicaban estos viajeros académicos, entendiéndose a sí mismos como agentes del desarrollo, y por ello opinando sobre dinámicas socioeconómicas, que trascendían sus especialidades, como si la pretensión de objetividad de la toma de datos se trasladara hacia la lectura del contexto político-económico en que esos datos son tomados.

En medio, la figura femenina se desdibuja en la peligrosa paradoja implícita en su reconocimiento. Si la mujer existe como protagonista, si su trabajo es de tal relevancia que no puede omitirse, entonces el Estado falla y la ciencia es imposible.

\section{FORTINERA, PRINCESA, MADRE Y TERRITORIO}

Uno de los aspectos recorridos por el feminismo es el error de pensar un universal homogéneo detrás del término "mujer". En el mismo sentido, la homologación tierra-mujer da cuenta de asimilaciones diferentes. Núñez ("The 'She-Land") analizó el quiebre del territorio en la década de los 30, cuando el control estatal apeló a metáforas femeninas para la ruralización del sur chileno y el establecimiento de los Parques Nacionales a ambos lados de la cordillera, como una actualización de la construcción de fronteras varias décadas después del período analizado, pero igualmente ligada a la lógica de esa conquista primigenia. El presente estudio agrega a ello que esta feminización de la década de los 30 se apoya en una feminización previa, relacionada con la apropiación misma del espacio, que en los 30, en todo caso, modifica su significación. 
Ahora bien, la temporalidad de las metáforas citadas por Núñez contiene cronologías propias. Las sociedades rurales del sur chileno remiten a las primeras organizaciones humanas, que desde hace miles de años vinculan la reproducción humana a la fertilidad del terreno, en la figura de "madre tierra", apelando a lo ancestral en la imagen que instalan. La mujer representante de los Parques Nacionales es otra. Si buscamos el hito fundacional que da origen a este tipo de áreas naturales protegidas, lo encontramos en 1872, cuando se crea la primera gran reserva natural protegida del mundo, el Parque Nacional de Yellowstone, en Estados Unidos. En la normativa que da origen a este ordenamiento se señala que se hace esta reserva como "espacio virgen" para el goce del pueblo, una idea que Fortunato encuentra replicada en los Parques Nacionales argentinos.

Espacio virgen, que remite a un cuerpo virgen que, implícitamente, es joven. Cuyo destino es ser base de disfrute de otros. Esta idea se liga a una imagen presente en el citado texto de Hudson, pues el autor señala que la Patagonia debe pensarse como un ser mítico, permanentemente joven y salvaje. Así relata su vivencia en territorio patagónico

Es duro vivir en el seno de una Naturaleza indomada o sometida a medias, pero hay en ello una maravillosa fascinación. Desde nuestro confortable hogar en Inglaterra, la Naturaleza nos parece una paciente trabajadora, obedeciendo siempre sin quejarse, sin rebelarse nunca y sin murmurar contra el hombre que le impone sus tareas; así puede cumplir la labor asignada, aunque algunas veces las fuerzas le fallen ¡Qué extraño resulta ver esta naturaleza, insensible e inmutable, transformada más allá de los mares en una cosa inconstante y caprichosa, difícil de gobernar; una hermosa y cruel ondina que maravilla por su originalidad y que parece más amable cuanto más nos atormenta... A veces es presa del furor que le causan las indignidades a que la sujeta el hombre podando sus plantas, levantando su suelo blando, pisoteando sus flores y su hierba. Entonces adopta su más negro y temible aspecto, y como una mujer hermosa que en su furia no tiene en cuenta su belleza, arranca de raíz los más nobles árboles y levanta la tierra esparciéndola por las alturas. (78-79)

Una mujer joven, que debe ser dominada para dar posibilidad al disfrute. La violación aparece como condición misma del existir. Esta imagen joven y mítica se cita en la constitución de los Parques Nacionales con el agregado de la fragilidad como argumento de tutelaje, y ello se instala desde una política

Feminismo/s 31, junio 2018, pp. 205-230 
que, como Zusman señala, es además panamericana. La figura femenina que fluctúa entre la ondina y la princesa es interesante, porque en las sucesivas imágenes de viajeros que recorren la zona, editadas en guías de viajes o revistas de medios de trasporte, como los ferrocarriles, los cuerpos que se dibujan visitando el lugar son jóvenes y deportistas. Visitante de una naturaleza que se cuida en montañas que se conquistan.

Cuerpos con una belleza constituyente de discursos políticos, que en su presencia justifican que la magnificencia del lugar requiere de ciertas personas específicas para disfrutarlo. Este imaginario llega a tal profundidad que en el Parque Nacional Nahuel Huapi, en Argentina, en la década del los 40 se crea una organización para enseñar a los pueblos originarios y a las poblaciones empobrecidas a disfrutar del paisaje (Mendez y Podlubne 1). La lectura política sobre los Parques Nacionales ha sido indagada discutiendo el modo en que el reconocimiento de una naturaleza impoluta sirvió a discursos nacionalistas (Klubock; Nouaeillez; Diegues). Menos evidente es la lectura sobre los análisis relacionados a los "cuerpos permitidos", con visitantes ideales que contrastan con el imaginario de la mujer (y la sociedad) que vive.

En la revista "En viaje" del Ferrocarril de Chile, se observa la enorme distancia entre la mujer burguesa que viaja, y la campesina que vive y hace producir esa tierra del sur devenida en madre-nutricia. La campesina se dibuja con un fenotipo que remiten a poblaciones originarias, pero además se la considera guardiana moral del deber-ser de las mujeres, explicitando la forma en que la promiscuidad se multiplicaba en los ordenamientos urbanos. De este modo, la población local, subalternizada, era además doblemente responsable de responder a las formas más duras del modelo patriarcal (Núñez, "The 'She-Land" 1455-1456).

Algo similar podemos encontrar en el espacio patagónico en el siglo XIX. El carácter femenino desdoblado, entre la fortinera esforzada y la Patria en riesgo, remite a la reflexión de Amorós, quien sostiene que la política de galantería, que torna el discurso de fragilidad en obligaciones masculinas de atención, fue una suerte de discriminación positiva que mujeres del siglo XIX pudieron establecer. Esa galantería, que alude a elementos de amor romántico destinado, en este caso, a la Patria, no se toma como parte de la relación que se establece con las fortineras, mucho más asimilables a la noción femenina construida desde las prácticas de esclavitud observadas por Rich, donde las

Feminismo/s 31, junio 2018, pp. 205-230 
mujeres también debían ser fuertes y poner su esfuerzo, tiempo y cuerpo al servicio de la delicadeza del ama blanca.

Paternalismo y colonialismo se cruzan en los espacios de frontera donde las mujeres, sin derecho a su cuerpo y a su tiempo, son especialmente cosificadas. Las fuentes de la Campaña de 1879 remiten a la mujer como parte de los bienes en disputa. Ella y los niños se mencionan robados de una y otra de las parcialidades, junto a bienes y animales, y en las sucesivas referencias se las incluye en listados mezclados que consolidan su imagen como botín (Raone 2: 280).

El cuerpo de la mujer que vive y representa la conquista a fines del siglo XIX es diferente al cuerpo de la burguesa-princesa referencia de la instalación de los Parques Nacionales en los años 30. El cuerpo de la fortinera, como el de la esclava, está hipersexualizado en múltiples niveles, y de este modo pierde agencia.

Las fuentes de la conquista reconocen la sexualidad forzada a la que es sometida la cautiva, en la condenada falta de moralidad que se atribuye a la población originaria. Pero la retórica romántica oculta esto en los espacios estatales. En los fortines lo femenino se presenta cubierto de decoro, citando actividades de cuidado y otorgando la figura de "esposa" a la compañera del soldado. El poema de Raone, quien en su obra refiere a que entre estas mujeres se encontraban nativas secuestradas tras la destrucción de sus poblaciones, da cuenta del carácter moral que subyace al reconocimiento del esfuerzo, a la negación de conflictos y naturalización del dominio sexual.

Siguió las huellas del marido, un día.

Y en el desierto se encontró azorada;

Giró en torno con angustia la mirada

Y sólo cielo y pampa encontró a porfía.

Más no la amilanó por eso su destino

Ser de su hombre -lo juró sincera-

Amante esposa fiel y eterna compañera

Consuelo en el pesar, de pena: olvido

Y es el "guri" -flor del desierto aparecido-

Lo que justifica la esperanza de esa espera.

Solícita mujer que a cualquier hora

fue bálsamo que consoló al herido

Alondra que cantó en el nido

Alegrando el campo con su voz sonora

Feminismo/s 31, junio 2018, pp. 205-230 
Luz en las sombras de ese pobre rancho

Que ella iluminó sin dar jamás reposo

A ese cuerpo que entregó al esposo

Con juramento fiel y por vida entera

En la angustiosa "línea de frontera"

Donde el sufrir es ley y cumplimento. (Raone 3: 314)

Las memorias de 1914 del Teniente Coronel de la Expedición, Eduardo Ramayon rescatan un reconocimiento que el romance omite, el rol que detentaban las mujeres les permitió, durante el proceso de conquista, solicitar raciones del ejército como si fueran parte del cuerpo militar. El autor destaca que las mismas eran mínimas, de modo que era un reconocimiento muy básico. Remite al discurso moral al señalar que muchas mujeres obtenían otros ingresos dando servicios a la tropa en general, como lavado de ropa. No hay cita a servicios sexuales en la pudorosa mención ${ }^{16}$. El militar denuncia y reclama que este reconocimiento, además de ínfimo fue efímero. "Una vez que todo fue paz y fraternidad, porque habían terminado las guerras, la situación de las pocas sobrevivientes quedó completamente definida de las listas en que figuraban y su no admisión en los cuarteles." (22)

El lugar reconocido a las mujeres durante la conquista se niega en el diseño del desarrollo sobre el que se avanza reconocida la pacificación. Esto se profundiza en las posteriores significaciones donde el territorio se presenta sin "capacidades" en tanto no sea gestionado en forma externa.

Desde el feminismo de frontera se presenta la particularidad del paternalismo como cambiante y actualizador del colonialismo en el territorio. La fortinera, como estereotipo del imaginario territorial, reaparece en la construcción permanente de fronteras internas, y muchas de las discusiones relativas a planificaciones y reconocimientos aún reproducen la invisibilidad a los órdenes domésticos de la producción (Michel y Núñez 258-269).

16. El listado de actividades a las que refiere Ramayon da cuenta que las obligaciones contractuales de estas mujeres era "acudir prontamente al primer llamado del oficial o sargento de guardia; asistir sin que faltara una sola -porque una clase recorría los ranchos- a las fiestas a los bailes que se daban en los cuarteles en los días de la patria, o en los aniversarios de las acciones de guerra en donde había tomado parte el cuerpo, como igualmente también, cuando se producía alguna muerte, se les hacía cumplir con la exigencia de concurrir a los velorios, rezar con unción y elevar sus plegarias fervorosas por el alma del finado"(22).

Feminismo/s 31, junio 2018, pp. 205-230 


\section{HACIA EL FEMINISMO DE FRONTERA}

La idea de feminismo de frontera propone que un reconocimiento territorial resulta configurador de las formas locales del paternalismo, en tanto se apoya en dinamismos de colonización ligados a la violencia de una conquista que, entre otros abusos, naturaliza la violencia sexual. Gilliam (166) recorre las teorías que apelan a los "excesos en los abusos" como configuradores de raza y cultura en las naciones americanas, denominándola "Gran teoría del esperma en la formación nacional", que justifica el orden social asimétrico en tres niveles, que se articulan a las diferencias que reconocemos en las mujeres de la frontera.

1. El papel de la mujer negra es rechazado en la formación de la cultura nacional.

2. La desigualdad entre hombre y mujer es erotizada.

3. La violencia sexual contra las mujeres negras ha sido convertida en un romance.

Podríamos tomar los tres elementos para pensar el rol de las fortineras en el establecimiento y significación del territorio patagónico y del país. Son la base de la posibilidad de una cultura que no las reconoce.

De allí que se puede pensar en un elemento esencial, algo de lo constitutivo que trasciende el sexismo para instalarse en el racismo como argumento de exclusión. La complejidad del caso de las fortineras es que ese racismo no apela a una etnia específica, porque no son solo mapuche, no son solo provincianas, no son solo europeas, son de todo un poco, unidas en los relatos al amor al marido devenido en amor a la patria. La frontera marca la diferencia, y en esto se constituye en una raza aparte, la de las mujeres en los bordes. Como mencionamos, lo racial es reconocido como antagónico en la parcialidad masculina. El racismo hacia las mujeres no implica su destrucción, sino el permanente sitio de abuso.

El feminismo de fronteras liga la proyección del carácter sexual de los cuerpos al territorio, sobre el cual lo único que se puede hacer es extraer información y dominarlo para su correcto desarrollo capitalista, sea por la agricultura, sea por la explotación de recursos, sea como paisaje virgen.

Raffestin desarrolla la idea de "geografía de poder" para dar cuenta de que las relaciones sociales, antes que las organizaciones estatales, son las 
que permiten recorrer las dinámicas de dominio. A ello agregamos que es una trama elaborada con los hilos del paternalismo. En el juego del reconocimiento social debemos tener en cuenta que la fortinera, como la frontera, resulta necesaria pero invisible, porque en cuando deviene observable, da cuenta de la debilidad de lo que se supone fuerte en el relato de poder. Así, es la red social que llena las organizaciones territoriales, la responsable de sostener la invisibilidad, en tanto sostiene la estructura de control.

La idea de recurso se tensiona desde esta perspectiva, el mismo autor evidencia que no existe algo así como los recursos naturales, en tanto los mismos son inventados según las sociedades que los inscriben como tales. La Patagonia, desde la década de los 30, ha sido presentada como espacio lleno de recursos energéticos e hidrocarburíferos, antes que como territorio poblado. La falta de personas se repite como característica, imponiendo límites al reconocimiento de las capacidades instaladas. El cambio en estas fronteras parece gestionarse desde impulsos externos.

El complejo carácter del cambio en los territorios de frontera ha sido explorado por Balibar, mostrando que la frontera necesita reconocerse como estable, lo cual quita posibilidad de gestionar su propio devenir. Lo femenino y lo fronterizo se confunden en esta similitud. Las mujeres, en el romance abnegado, aparecen limitadas, en tanto el cambio no puede pasar por sus acciones. Son sostenedoras de un orden predeterminado, anclajes de lo fijo, parte de los recursos, que entonces las alejan de su rol como agentes del desarrollo.

La noción de feminismo de frontera permite pensar en cómo el establecimiento de lo fronterizo va marcando el reconocimiento social con bases sexistas. La frontera de la conquista devino en frontera interna, en los territorios de secano que, como muestran Conti y Núñez, aún se presentan con poblaciones necesitadas de tutelaje y con derechos políticos limitados (196219). En un modelo de Estado diferente, en la década de los 30, el ideal de mujer que estructura el reconocimiento de la frontera estatal es otro, que sostiene el modelo precedente en los sectores más subalternos, pero que plantea nuevas lógicas de inequidad en los procesos que se busca promocionar. Los feminismos de frontera no son fijos, sino que se resignifican y solapan a partir de las diferencias que las políticas buscan establecer, aunque comparte una sistemática limitación a agencia de lo caracterizado como femenino.

Feminismo/s 31, junio 2018, pp. 205-230 
Vale como ejemplo uno de los romances clásicos patagónicos, en el que se recuerda en una hermosa zamba a "La Pasto Verde" referida por Wullich, una fortinera neuquina, inmortalizada por el cobijo que daba y no por ser quien descubrió el petróleo en Plaza Huincul, uno de los principales centros actuales de extracción. Desde apelaciones a menciones casuales, a referencias que marcan sistemáticos avisos de la paisana respecto a puntos donde brotaba petróleo, su acción es omitida en el registro oficial del desarrollo económico, que refiere, sí, a la actividad de los varones que preguntaron sobre este tema a la ex fortinera. Ella, como leyenda, es recordada, pero no como actriz central de la economía local y nacional. Su nombre, Carmen Funes, es recuperado en un tono menor que su imagen como fortinera, que es de hecho su marca de legitimidad para inmortalizarse en el romance. Carmen resulta invisible como actriz del desarrollo por el propio romance que la reconoce; ese ocultar a partir de un reconocimiento sesgado también opera sobre el territorio.

Otra imagen ilustrativa es la del cartel oficial, en una de las estaciones de las vías de ferrocarril que atraviesa la Patagonia desde el océano Atlántico hasta la cordillera, presente en la figura 1.

El tiempo natural del territorio devenido en frontera, con la base de la fronteriza aún presente, es el del retraso. Se acepta que nada llegue a horario. Se eterniza la adjetivación de territorio de frontera, alejado del lugar del cambio, como lugar de progreso. No hay reclamo a cambio de infraestructura, hay una naturalización de un no-pasar que se toma como referencia de las sociedades locales. La única posibilidad de cambio se presume externa y tutelada.

Femenías (9), al dar cuenta de los perfiles del feminismo latinoamericano, evidencia que lo que tienen en común es una violencia que no se termina de desmantelar, a pesar de las denuncias y los cambios. En este escenario, la reflexión sobre la frontera -interna o internacional- como aún feminizada puede permitir descubrir uno de los puentes más sólidos y más ocultos en el deslizamiento entre el uso de la tierra y el disciplinamiento de la población. Esta es el centro de la noción de "feminismo de frontera". 
Feminismo de frontera. La construcción de lo femenino en territorios de integración tardía
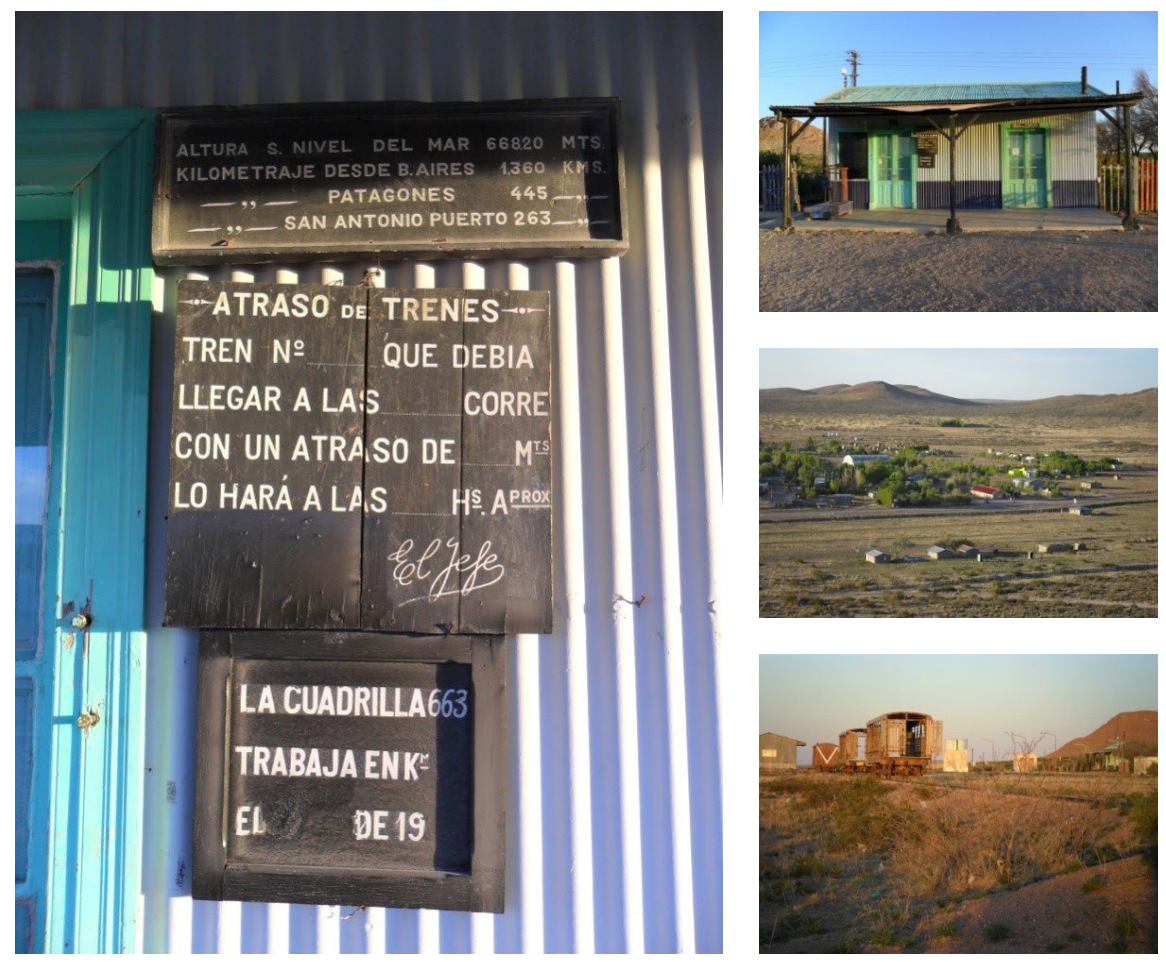

Figura 1: Cartel en Estación de Ferrocarril en Sierra Colorada, Provincia de Río Negro, e imágenes del pueblo. 2011. Fotos Matías Skulj.

\section{REFERENCIAS BIBLIOGRÁFICAS}

Amorós, Celia. Mujeres e imaginarios de la globalización. Reflexiones para una agenda teórica global del feminismo. Argentina: Homosapiens, 2008.

Balibar, Étienne. "Fronteras del mundo, fronteras de la política". Alteridades 15.30 (2005): 87-96.

Barriteau, Violet. "Aportaciones del feminismo negro al pensamiento feminista: una perspectiva caribeña". Boletín Ecos 14 (2011). 4 marzo 2017. <http:// www.fuhem.es/ecosocial/boletin-ecos/numero.aspx?n=14>

Bordo, Susan. "The Cartesian Masculinization of Thought". Signs 11.3 (1986): 439-456. 
Feminismo de frontera. La construcción de lo femenino en territorios de integración tardía

Butler, Judith. El género en disputa. El feminismo y la subversión de la identidad. España: Paidos, 2007.

Conti, Santiago y Paula Núñez. "Historia marginal en el escenario presente". Sombras del desarrollo. La Patagonia de la energía y la formación de la provincia de Río Negro. Comp. Paula Núñez. Río Negro: IIDYPCA-UNRN, 2016. 196-219.

De la Fuente, Diego. Primer Censo Argentino 1869. Argentina: Instituto Nacional De Estadísticas y Censos, 1872.

-. Segundo Censo de la República Argentina 1895. Argentina: Instituto Nacional De Estadísticas y Censos, 1898.

Diegues, Carlos. El mito moderno de la naturaleza intocada. Brasil: Center for Research on Human Population and Wetlands, 2005.

Dillon, Susana. Las locas del camino. Córdoba: Universidad de Río Cuarto, 2005. Doering, Adolfo. Informe oficial de la comisión científica agregada al estado mayor general de la expedición al rio Negro (Patagonia). Realizada en los meses de Abril, Mayo y Junio de 1879, bajo las órdenes del General D. Julio A. Roca. Entrega I- Zoología. Buenos Aires: Imprenta de Osvaldo y Martínez, 1881.

Ebelot, Albert. "Introducción". Informe oficial de la comisión científica agregada al estado mayor general de la expedición al rio Negro (Patagónia). Realizada en los meses de Abril, Mayo y Junio de 1879, bajo las órdenes del General D. Julio A. Roca. Entrega I- Zoología. Ed. Adolfo Doering. Buenos Aires: Imprenta de Osvaldo y Martínez, 1881. VII-XXIV.

Femenías, María Luisa (comp.). Perfiles del feminismo latinoamericano. Volumen 2. Buenos Aires: Catálogos, 2005.

Foerster, Rolf y Julio Vezub. "Malón, ración y nación en las pampas: el factor Juan Manuel de Rosas (1820-1880)". Historia 44.2 (2011): 259-286.

Fortunato, Norberto. "El territorio y sus representaciones como fuente de recursos turísticos. Valores fundacionales del concepto de "parque nacional". Estudios y Perspectivas en Turismo 14. 4 (2005): 314-348.

Gilliam, Angela. "Black feminist perspective on the sexual commodification of women in the new global culture". Black Feminist Antropology. Theory, politics, praxis and poetics. Ed. Irma McClaurin. USA: Rutgers University Press, 2001. 150-170.

Haesbaert, Rogerio. El mito de la desterritorialización: del fin de los territorios a la multiterritorialidad, México: Siglo XXI, 2011. 
Harvey, David. "La experiencia del espacio y el tiempo". David Harvey. La condición de la posmodernidad. Investigación sobre los orígenes del cambio cultural. Buenos Aires: Prometeo, 1998. 225339.

Hudson, Guillermo. Días de ocio en la Patagonia. Buenos Aires: El Elefante Blanco, 1997 [1893].

Hunt, Krista y Kim Rygiel. (En)Gendering the War on Terror: War Stories and Camouflaged Politics. Londres y Nueva York: Routledge, 2008.

Iuorno, Graciela y Edda Crespo. Nuevos Espacios, Nuevos Problemas. Neuquén: Educo, 2008.

Klubock, Tomas. La Frontera: Forests and ecological conflict in Chile's Frontier territory. Durham: Duke University Press, 2014.

Lee, Marti y Ed Madden. Irish Studies: Geographies and Genders. Gran Bretaña: Cambridge Scholars Publication, 2008.

Lewis, Reina y Sara Mills. Feminist postcolonial theory. A reader. Nueva York: Routledge, 2003.

Lois, Carla. "Técnica, política y 'deseo territorial' en la cartografía oficial de la Argentina (1852-1941)". Scripta Nova X.218 (2006). 7 agosto 2013.

Lorentz, Pablo Y Gustavo Niederlein. Informe oficial de la comisión científica agregada al estado mayor general de la expedición al rio Negro (Patagonia). Realizada en los meses de Abril, Mayo y Junio de 1879, bajo las órdenes del General D. Julio A. Roca. Entrega II- Botánica. Buenos Aires: Imprenta de Osvaldo y Martínez, 1881.

Méndez, Laura y Podlubne Adriana. "Atraer para Educar Recreando. El Proyecto Ayekan Ruca en San Carlos de Bariloche. 1934-1955”. 3. Jornadas de Historia de la Patagonia. Universidad Nacional del Comahue, Bariloche 6-8 noviembre 2008. 4 julio 2015. [http://www.hechohistorico.com.ar/Trabajos/Jornadas\%20 de\%20Bariloche\%20-\%202008/Mendez-Podlubne.pdf]

Michel, Carolina y Paula Núñez. "Planificación y cambio en áreas rurales norpatagónicas". Reconfiguraciones territoriales e identitarias. Miradas de la historia argentina desde la Patagonia. Coord. Marisa Moroni, Mariana Funkner, Leonardo Ledesma, Eric Morales Schmuker y Hernán Bacha, Santa Rosa: Publicaciones UNLPam, 2017. 258-269.

Napp, Ricardo. La República Argentina, para ser presentado en la Exposición de Filadelfia. Buenos Aires: Sociedad Anónima, 1876.

Navarro Floria, Pedro. Patagonia: Ciencia y Conquista. La mirada de la primera comunidad científica argentina, General Roca: PubliFaDeCS/CEP, 2004. 
Feminismo de frontera. La construcción de lo femenino en territorios de integración tardía

--. "Territorios marginales: los desiertos inventados latinoamericanos. Representaciones controvertidas, fragmentadas y resignificadas". Los desiertos en la historia de América. Una mirada multidisciplinaria. Ed. Deni Trejo. México: Universidad Michoacana de San Nicolás de Hidalgo, Universidad Autónoma de Coahuila, 2012. 207-226.

Nouaeillez, Gabriela. "Patagonia as a Borderland: Nature, Culture and the Idea of State". Journal of Latin American Cultural Studies 8.1 (1999): 35-49.

Núñez, Paula. "Latinoamérica, trazado de límites y desigualdades". Revista Venezolana de Estudios de la Mujer 14.33 (2009): 55-70.

-. Distancias entre la ecología y la praxis ambiental. Una lectura crítica desde el ecofeminismo. La Plata: Edlup, 2011.

- . "The 'She-Land', social consequences of the sexualized construction of landscape in North Patagonia". Gender, Place and Culture: A Journal of Feminist Geography 22.10 (2015): 1445-1462.

Ockier, María. "Marcas de género y clase en el discurso militar. A propósito de las fortineras". Historias de luchas, resistencias y representaciones. Mujeres en la Argentina, siglos XIX y XX. Comp. María Bravo, Fernanda Gil Lozano y Valeria Pita. Tucumán: EDUNT, 2008. 307-333.

Pichel, Vera. Las Cuarteleras. Cuatro mil mujeres en la Conquista del Desierto, Buenos Aires: Planeta, 1994.

Podgorny, Irina. "La Patagonia como santuario natural de la ciencia finisecular". REDES 6 (1999): 157-176.

Quijada, Mónica. "Nación y territorio: la dimensión simbólica del espacio en la construcción nacional argentina. Siglo XIX”. Revista de Indias 60. 219 (2000): 373-394.

Raffestin, Claude. Por una geografía de poder. México: El colegio de Michoacán, 2014.

Ramayon, Eduardo. El Fortín (Conferencia). Buenos Aires: Guillermo Kraft, 1914. Raone, José. Fortines del Desierto. Mojones de Civilización. Tomos I, II y III. Buenos Aires: Editorial Lito, 1969.

Rich, Adrienne. On Lies, Secrets, and Silence: Selected Prose 1966-1978. New York: W.W. Norton, 1979.

Saldivar-Hull, Sonia. "Feminism on the Border: From Gender Politics to Geopolitics". Criticism in the Borderlands. Studies in Chicanpo Literature, Culture and Ideology. Ed. Héctor Calderón and Jose Saldívar. Durham and London: Duke U.P., 1991. 203-220. 
Feminismo de frontera. La construcción de lo femenino en territorios de integración tardía

Sarmiento, Domingo. Facundo. Civilización o barbarie en las pampas argentinas. Chile: El progreso, 1845.

Sckmunck, Romina. "Mujeres Mapuche: Signos de identidad". III Jornadas del Centro Interdisciplinario de Investigaciones en Género, 25-27 septiembre 2013, Universidad Nacional de La Plata, Argentina. 7 diciembre 2017. <http://www. memoria.fahce.unlp.edu.ar/trab_eventos/ev.3414/ev.3414.pdf>

Vera Gajardo, Antonieta. "Moral, representación y 'feminismo mapuche': elementos para formular una pregunta". Polis 38 (2014). 12 marzo 2018.

Wullich, Mariano. "'La Pasto Verde', cuartelera y señora en Plaza Huincul. La fortinera que se convirtió en posadera fue inmortalizada en una gran zamba". Diario La Nación. Sección Campo 8 Junio 2013. 7 de abril de 2017. <https://www.lanacion.com.ar/1589322-la-pasto-verde-cuartelera-y-senora-en-plaza-huincul>

Zusman, Perla. "Panamericanismo y conservacionismo en torno al viaje de Theodore Roosevelt a la Argentina (1913)". Modernidades 11 (2011). 5 junio 2012. 